\title{
State your interests
}

\author{
There is widespread engagement of the scientific community with industry. Statements of competing interest \\ are, therefore, an important mechanism for readers to assess real and perceived biases in published research and \\ commentary.
}

A t Nature Food we require authors to declare competing interests that could undermine, or be perceived to undermine, the objectivity and integrity of a manuscript. The policy covers primary research, reviews and opinion pieces. The aim is to provide transparency to facilitate readers, including peer reviewers, in making an assessment for themselves of potential bias within a manuscript.

Competing interests can be financial or non-financial. Examples of competing interests that are financial include research support from or employment by organizations that may gain or lose financially from the publication, and personal financial interests that relate to the research. Non-financial competing interests include unpaid memberships of governmental, non-governmental, advocacy or lobbying organizations related to the work, and unpaid advisory positions to commercial organizations. These examples are not exhaustive, and more information on the Nature Portfolio's approach to competing interests can be found here.

The Nature Food community is well aware of conflicting views related to the food industry, and dialogue around engagement of researchers with the food industry sometimes reaches fever pitch among us. And rightly so. A spectrum of principled views is critical to community debate, inclusive dialogue and progress. The concern is, however, that views on the matter of industry engagement become irreparably divisive - and those divisions impact the scientific process, how we educate the next generation of food system scientists and public confidence in our community.

Over 20 years ago, Marion Nestle addressed some of these issues, noting ubiquity of the food industry's backing of research and researcher activities in the fields of nutrition, food and agriculture ${ }^{1}$. Nestle noted that corporate financial support doesn't "necessarily cause recipients to bias their results, opinion or actions", but cannot help but raise questions around genuine or perceived independence of the recipient. A step in dealing with these questions, in journals like Nature Food, is disclosure of both financial and non-financial competing interests at all stages of the manuscript handling process. Even authors who request double-blind peer review or are bound by confidentiality agreements must provide a statement on their submissions disclosing financial or non-financial interests.

Nature Food requests an explicit statement of the existence of competing interests from authors - nothing more. The author must lay the salient and sufficient facts on the table to inform an assessment of their objectivity by the reader. Competing interest statements do not, and should not, further elucidate the motivations of why researchers have, for example, engaged with industry.

It is those motivations that perhaps are most contentious. Declarations of project funding from industry and entrepreneurial activities of researchers on the back of their innovations are arguably best suited to the standard competing interest statement.
They tend to be rather clear-cut. However, employment within the food industry, and the direction of paid and unpaid consultancies are a little more challenging to decipher from the standard competing interest statement. Stuckler and Nestle acknowledge those public health advocates who work for and with food companies to try to enact positive change from within ${ }^{2}$. Among our community are those that see the food industry as part of the problem, but also part of the solution. And among our community are those that see this position as naive, "doomed to fail"'. The competing interest statement does not speak to any such personal viewpoints or motivations nor should it. This kind of detective work would bring a dangerous level of subjectivity to the publication of scientific work.

Our journal Nature Food strives to be a forum for open discussion where informed opinions are welcome. We wish to serve our diverse community with the very best of primary research and commentary - and we insist that all formats are supported by a clear competing interest statement. The statement has a defined purpose to put before the reader the existence of competing interests and, ultimately, it is a mechanism to allow the reader to judge the science for itself.

Published online: 24 February 2022 https://doi.org/10.1038/s43016-022-00474-2

References

1. Nestle, M. Publ. Health Nutr. 4, 1015-1022 (2001).

2. Stuckler, D. \& Nestle, M. PLoS Med. 9, e1001242 (2012). 